\title{
Is there a Relationship Between HMO \\ Quality of Care and Financial Performance? \\ Evidence from Texas HMOs
}

Troy Quast

Sam Houston State University

tcq001@shsu.edu

2010-12

Objective. To examine the relationship between HMO financial performance and quality of care.

Study Setting. Selected commercial HMOs in Texas from $2000-2008$.

Study Design. Ordinary least squares (OLS) and instrumental variable (IV) fixed effects regression analyses were performed to assess the relationship between selected HEDIS quality measures and HMO financial performance measures.

Data Collection/Extraction Methods. Two secondary sources were used: Guide to Texas HMO Quality produced by the Texas Department of State Health Services and HMO financial reports to the Texas Department of Insurance.

Principal Findings. The regression results generally suggest a positive association between selected child health HEDIS measures, but no association with female health measures.

Conclusions. The quality of care provided by an HMO may be influenced by its financial condition. As such, policy efforts to restrict insurance company profits may be improved by ensuring that the quality of care is not diminished.

Key Words. HMOs, quality, profits, HEDIS 
The profits earned by health insurance companies have been under intense scrutiny by policymakers and the general public. Many have criticized insurance companies for attempting to earn unfair profits by overcharging consumers. In February 2010, the Obama administration issued a report entitled, "Insurance Companies Prosper, Families Suffer: Our Broken Health Insurance System," which noted that from 2000 to 2009, profits for the ten largest health insurance companies increased ten times faster than consumer inflation.

However, attempts to reduce insurance company profits could affect the quality of care that they provide to their enrollees. For instance, in response to lower profits, insurance companies could potentially reduce or eliminate expenditures that are directly related to quality of care. If so, reductions in insurance company profits could be accompanied by lower quality of care.

This study investigates whether there is a relationship between the profitability of an HMO and the quality of care that its enrollees receive. The sample is comprised of health maintenance organizations in Texas from 2000 to 2008. Quality of care is proxied by HEDIS compliance rates for selected child and female health measures, while profits are measured both on a dollar and percentage basis. Annual data are used that are disaggregated by market area.

The results suggest that there is a statistically significant relationship between profits and some measures of quality. Specifically, the child health measures used here are positively related to profits, in that increases (decreases) in profits are associated with increases (decreases) in quality. By contrast, there is not a statistically significant relationship between the available female health measures and profits. Further, for the child health measures, instrumental variable models that attempt to address to the potential endogeneity of quality and profits are consistent with the possibility that changes in profits have a causal effect on quality of care.

Relatively few papers have examined the potential relationship between $\mathrm{HMO}$ quality of care and profits. Born and Simon (2001) examine 200 commercial HMOs in 1997 and find that higher profits are associated with higher HEDIS scores in the following year. Using data from 1999, Scanlon et al (2005) investigate whether the ownership status of an $\mathrm{HMO}$ affects the quality of care it provides. They find that including HMO profits as an explanatory variable in their regression equation does not alter the relationship between ownership status and quality of care. Born and Geckler (1998) find that HMOs with a higher medical (administrative) expense ratio tend to provide higher quality care.

This study potentially improves upon the existing literature in a number of dimensions. First, the data allow for a panel fixed effects analysis, which controls for time-invariant, market specific factors and provide a more precise measure of the effects of changes in profits for a given HMO (rather than differences in profits across HMOs). Second, the use of data disaggregated by both HMO and market area may allow for a more precise measure of the local effects of a change in HMO profitability. Third, the use of an instrumental variable model potentially addresses endogeneity between quality and profits which, if not addressed, may lead to biased estimates. Further, if properly specified, the instrumental variable model can provide insight into the causal relationship between profits and quality. 


\section{CONCEPTUAL FRAMEWORK}

There are two primary means by which the profitability of an HMO could be related to the quality of care it provides to its enrollees. First, the HMO may take actions in response to profit fluctuations that directly affect the quality of care. Second, the HMO may indirectly affect the quality of care via policies or decisions that impact its network providers.

As noted by Scanlon et al (2000) and Maeng et al (2010), HMOs may be able to significantly influence the quality of care that their enrollees receive. For instance, HMOs can implement enrollee interventions, such as reminder phone calls or mailings that encourage enrollees to receive care. It may be the case that HMOs are more (less) likely to incur the costs of these types of programs during periods of relatively high (low) profits. Another example of a direct effect from HMOs is the offering of prevention programs, such as smoking cessation programs. Again, such programs may be less likely to be undertaken during periods of relatively poor profits. Finally, during periods of economic duress, HMOs may be less likely to undertake efforts at assessing enrollee needs.

As the primary medical contact for enrollees, physicians likely have the biggest impact on quality of care. At first glance, it may appear that the financial performance of an HMO would not affect physician behavior. However, there are a number of channels by which HMO profitability may impact the quality of care provided by physicians.

First, as noted in Hillman (1991), HMOs may award physicians some form of bonus payments if there are surpluses in referral accounts or if a physicians meets some productivity goal. As the size of these bonuses may fluctuate with profits earned by the HMO, physicians may have a greater incentive to meet HEDIS goals during periods of high profits.

Another potential factor is the threat of a physician being dropped from an $\mathrm{HMO}$ network. Most physician contracts allow for termination without cause (typically with a 60- to 90-day notice). Thus, there may an incentive during especially poor financial periods for physicians to less aggressively treat enrollees and thus reduce quality.

Finally, physician contracts with HMOs can include incentive withhold pools, whereby the HMO withholds a fraction of the payment due to the physician. Then, at the end of the year, if the utilization rates for that physician fall within certain guidelines, the HMO may pay the physician the amount it has withheld. However, as shown in a sample contract reprinted in Kongstvedt (2003), the HMO, at its discretion, may choose to not pay the withheld amount. One of the scenarios outlined in the contract in which the HMO may not pay the withheld amount is if the HMO needs to assure its financial stability. Thus, if a physician has such a contract and believes the $\mathrm{HMO}$ is under financial duress, the physician may be less likely to encourage care under the fear that they will not recoup the withhold payment. According to the HMO CEO interviewed in Diamond (2009), his HMO reimburses doctors based partly whether the HMO "holds costs down." 
The sample in this study is commercial HMO's in Texas during the $2000-2008$ period. The two data sources employed are the annual reports Guide to Texas HMO Quality published by Texas Department of State Health Services and financial data reported to the Texas Department of Insurance. The data are measured at the year - HMO - market area level

The top section of Table 1 details the child and female health HEDIS measures reported in the Guide for Texas HMO Quality and used in this study. The child utilization measures are prenatal visits, six or more well-child visits in the first 15 months, one visit in the previous year for children aged three to six, and selected childhood immunizations. ${ }^{1}$ The female health measures are postpartum visit and breast cancer screening. ${ }^{2}$

The profitability measures employed include profits per-member-per-month, as well as the medical expense (total medical expenses divided by total revenues) and the administrative expense ratio (total medical expenses divided by total revenues).

Additional control variables are included to control for other factors thought to affect the HEDIS scores. For example, enrollee characteristics may be related to the quality measures. Thus, the total number of enrollees, the proportion of enrollees in the relevant age and (if applicable) gender group, and the proportion of enrollees by type of coverage (Medicare and group) are included as explanatory variables. The supply of physicians may also influence HEDIS compliance rates, thus the number of primary care doctors and the number of the relevant specialists per enrollee are also employed as explanatory variables. Finally, as noted by Pawlson et al (2007), the way in which the HEDIS data are collected (administrative only versus administrative and chart review) may influence the compliance rate. Thus, an indicator variable is included that equals one if the HEDIS score is based on administrative data and zero otherwise.

\section{METHODOLOGY}

Multiple regressions are estimated for each of the 11 HEDIS scores and the three profit measures, thus resulting in 33 regressions. The regressions take the following form:

$$
\text { hedis } \left._{i j t}=\beta_{0}+\beta_{1} \text { profit }_{i j t}\right)+\sum_{k} \beta_{k+2} \text { control variables } \text { kijt }+\gamma_{i}+\delta_{j}
$$

where, $i$ indexes the $\mathrm{HMO}, j$ indexes the $\mathrm{HMO}$, and $t$ indexes the year. As noted above, the included control variables vary according to the HEDIS measure used as the dependent variable.

The $\gamma$ and $\delta$ terms are $\mathrm{HMO}$ and market fixed effects, respectively. The inclusion of the $\mathrm{HMO}$ and market fixed effects implies that the estimates are measured holding constant any effects in an HMO or market that do not vary over the sample period. The observations are weighted by the number of member months for that HMO in that market in that year. Finally, the observations are clustered by HMO to account for the possibility of correlated disturbances within each HMO. 


\section{RESULTS}

Table 2 shows the coefficient estimates of the profit measure in the estimated regressions. The rows correspond to the HEDIS measure used in that regression, while the columns correspond to the financial performance measures. The top number in each cell corresponds to the coefficient estimate, while the bottom number is the corresponding standard error. The top rows contain the estimates HEDIS measures for child health, while the bottom two rows contain the female health measures.

\section{Child Health Measures}

As shown in the first column of Table 2, for all of the child health measures, when profits are used as the financial performance measure, the coefficient estimates are positive. This suggests that the HEDIS measures and profits on average move in the same direction. Nine of the estimates are statistically different from zero at a $10 \%$ significance level, while five are significant at the $5 \%$ level. Further, the magnitudes of some of coefficients are arguably practically significant. For instance, a one standard deviation increase in profits is associated with a roughly $8 \%$ increase in the $1^{\text {st }} 15$ months well-child score and a $7 \%$ increase in the score for children aged three to six. Likewise, a one standard deviation in profits is associated with a roughly $8 \%$ increase in the DTAP and HIB HEDIS scores.

The second column of Table 2 details the coefficient estimates when the medical expense ratio is used as the financial performance variable. Given the estimates in Table 1 and that increased values of this variable reflect lower profitability, it is not surprising that the coefficient estimates are all negative. ${ }^{3}$ However, only two of the nine estimates are statistically different from zero at a $10 \%$ significance level. Yet, the point estimates do suggest practical significance. For example, a one standard deviation increase in the ratio is associated with a roughly $5 \%$ decrease in the well-child measures.

Finally, the third column of Table 2 contains the coefficient estimates when the administrative expense ratio is used as the measure of financial performance. These estimates are generally even less statistically significant than those when the medical expense ratio is used.

\section{Female Health Measures}

The bottom two sets of rows in Table 2 show the results for the female health measures. In contrast with the estimates using the child health measures, these coefficient estimates lack both statistical and practical significance. When profits are used as the measure of financial performance, only the postpartum measure is remotely statistically different from zero ( $p$-value $=.185)$. However, the associated effect from a one standard deviation increase in profits is less than a $2 \%$ change. This pattern of insignificant results also holds for the estimates using the two expense ratios.

\section{Instrumental Variable Approach}

An important limitation of the estimates described above is that, while they provide information regarding correlations between the HEDIS measures and an HMO's financial performance, they may not correctly reflect causation. Specifically, while the results may indicate that the measures and profits 
move in the same direction, on the basis of the results above we cannot necessarily conclude that changes in profits are causing changes in the HEDIS scores.

One way to potentially address this concern is the use of an instrumental variable approach. To estimate the regression using this method, a variable must be found that (in the current context) is correlated with the financial performance measure and is only correlated to the HEDIS measure via its correlation to the financial performance measure.

For this analysis, the per-member number of Medicare inpatient days is used as an instrumental variable. Intuitively, this variable arguably meets the two criteria set forth above. First, one would expect that the number of inpatient days to be (negatively) correlated with profits. Second, it seems unlikely that the number of Medicare inpatient days would not be directly correlated with the child health and female health HEDIS measures used here.

While there is no direct test of the second criteria described above, one can test whether the candidate instrumental variable meets the first criteria. Using the test proposed by Stock et al (2002), the Medicare inpatient days variable does not appear to be valid for the regressions where the prenatal and child immunizations HEDIS measures are used. Thus, less weight should be placed on those estimates.

However, Table 3 indicates that the coefficient estimates from employing the instrumental variable approach are generally consistent with those in Table 2. For the child health measures, the coefficient estimates generally retain the same sign while the magnitudes of the estimates are typically larger.

As noted above, the instrument used here is imperfect and thus caution is warranted in interpreting these results. However, the estimates are consistent with the possibility that changes in an HMO's financial performance have a causal effect on the quality of care.

\section{DISCUSSION}

Given the current debate over the profits earned by health insurance companies, it may be helpful to determine whether changes in profits are associated with changes in the quality of care provided by the HMO. The results in this study suggest that, at least for some measures, there may be an association. While the instrumental variable results should be taken with caution, they do suggest the possibility that there exists a causal relationship between financial performance and quality.

One aspect of the results that is unclear is why an association is present for the child health measures, but not for the female health measures. While the results do not shed light on the reasons for this difference, one possible explanation could be the difference in provider types. While well-child visits are performed only by primary care practitioners, prenatal and postpartum visits are typically performed by OB/GYNs. There may be some difference in incentives between these provider types.

There are a number of important limitations to this study. First, the sample is limited to just one state and is over a relatively short period. A national analysis using market level could provide more insight. 
Second, the results are based on a small selection of child and female health quality measures. As such, it is not possible to interpret these results as representative of overall child and female health quality. Third, some HMOs did not report HEDIS measures in every year for every market in which they operated. If this lack of reporting was nonrandom, it may introduce some sample selection bias which could influence the results. Finally, the results do not shed any light as to by what mechanisms or channels does an HMO's financial performance influence the quality they provide. More detailed operating data could allow for a clearer look at this important issue.

1. Measures for IPV, pneumococcal conjugate, and Combination 3 vaccines were not included in the analysis because of an insufficient number of observations.

2. Cervical cancer screening and Chlamydia screening measures are only available starting in 2006 and 2007 , respectively.

${ }^{3}$ However, this is in contrast with Born and Geckler (1998), who find that HMOs that have higher medical expense tend to have a higher quality score. 


\section{REFERENCES}

Born, P., and C. Geckler. 1998. "HMO Quality and Financial Performance: Is there a Connection?" Journal of Health Care Finance 24: 65-77.

Born, P., and C. J. Simon. 2001. "Patients and Profits: The Relationship Between HMO Financial Performance and Quality of Care." Health Affairs 20 (2): 167-174.

Diamond F. 2009-11. "Review Panel Pays off for Colorado-Based Plan." Managed Care Magazine 56-57.

Hillman A. L., M. V. Pauly, K. Kerman, and C. R. Martinek. 1991. "HMO Managers' Views on Financial Incentives and Quality. Health Affairs 10 (4): 207.

Kongstvedt, P.R. 2003. Essentials of Managed Health Care. Jones \& Bartlett Learning.

Maeng, D. D., D. P. Scanlon, M.E. Chernew ME, T. Gronninger, W. P. Wodchis, and C. McLaughlin. 2010. "The Relationship Between Health Plan Performance Measures and Physician Network Overlap: Implications for Measuring Plan Quality." Health Services Research. 45 (4):1005-1023.

Pawlson L. G., S. H. Scholle and, A. Powers. 2007. "Comparison of Administrative-Only Versus Administrative Plus Chart Review Data for Reporting HEDIS Hybrid Measures." American Journal of Managed Care 13 (10): 553-558.

Scanlon D. P., E. Rolph, C. Darby and, H. E. Doty. 2000. "Are Managed Care Plans Organizing for Quality?" Medical Care Research and Review 57 (2): 9-10.

Scanlon D. P., S. Swaminathan and, M. Chernew. 2005. "Competition and Health Plan Performance." Medical Care 43 (4): 338-346.

Stock, J.H., J. H. Wright and, M. Yogo. 2002. A Survey of Weak Instruments and Weak Identification in Generalized Method of Moments. Journal of Business \& Economic Statistics 20 (4): 518-529.

U.S. Department of Health and Human Services. 2010. "Insurance Companies Prosper, Families Suffer: Our Broken Health Insurance System." [accessed on September 10, 2010] Available at: http://www.healthreform.gov/reports/insuranceprospers/index.html. 


\begin{tabular}{|c|c|c|c|c|}
\hline & \multicolumn{3}{|c|}{ Standard } & \multirow[b]{2}{*}{ Maximum } \\
\hline & Mean & Deviation & Minimum & \\
\hline \multicolumn{5}{|l|}{ HEDIS measures (percent) } \\
\hline Prenatal care $(\mathrm{N}=178)$ & 0.78 & 0.16 & 0.18 & 1.00 \\
\hline Well-child visits (1st 15 months) $(\mathrm{N}=210)$ & 0.50 & 0.16 & 0.00 & 0.87 \\
\hline Well-child visits ( $3-6$ years) $(\mathrm{N}=199)$ & 0.49 & 0.12 & 0.18 & 0.73 \\
\hline Child. Immun. - DTAP (N=153) & 0.34 & 0.18 & 0.00 & 0.85 \\
\hline Child. Immun. - MMR (N=153) & 0.70 & 0.18 & 0.00 & 0.97 \\
\hline Child. Immun. - HIB (N=210) & 0.43 & 0.19 & 0.00 & 0.95 \\
\hline Child. Immun. - hepatitis $B(N=153)$ & 0.20 & 0.18 & 0.00 & 0.90 \\
\hline Child. Immun. - VZV (N=153) & 0.67 & 0.17 & 0.00 & 0.95 \\
\hline Child. Immun. - combo 2 ( $N=153)$ & 0.14 & 0.15 & 0.00 & 0.81 \\
\hline Postpartum care $(\mathrm{N}=204)$ & 0.67 & 0.22 & 0.43 & 0.91 \\
\hline Breast cancer screening ( $N=231)$ & 0.67 & 0.07 & 0.31 & 0.84 \\
\hline \multicolumn{5}{|l|}{ Financial performance measures } \\
\hline Profits (PMPM) & 4.40 & 19.40 & -135.76 & 114.42 \\
\hline Medical expense ratio & 0.84 & 0.11 & 0.32 & 1.23 \\
\hline Adminstrative expense ratio & 0.16 & 0.11 & 0.03 & 0.91 \\
\hline \multicolumn{5}{|l|}{ Control variables } \\
\hline \multicolumn{5}{|l|}{ Entire HMO } \\
\hline$\%$ Medicare enrollees & 0.06 & 0.17 & 0.00 & 0.84 \\
\hline$\%$ group coverage enrollees & 0.84 & 0.25 & 0.08 & 1.00 \\
\hline$\%$ admin. HEDIS data collection & 0.84 & 0.36 & 0.00 & 1.00 \\
\hline \multicolumn{5}{|l|}{ Enrollees in 1st year of life } \\
\hline$\%$ of all enrollees & 0.01 & 0.002 & 0.003 & 0.02 \\
\hline \# primary care doctors per enrollee & 2.50 & 4.70 & 0.10 & 41.1 \\
\hline \# pediatricians per enrollee & 0.50 & 0.90 & 0.00 & 7.70 \\
\hline \multicolumn{5}{|l|}{ Enrollees aged 1-4 } \\
\hline$\%$ of all enrollees & 0.06 & 0.01 & 0.04 & 0.13 \\
\hline \# primary care doctors per enrollee & 0.60 & 1.40 & 0.02 & 10.7 \\
\hline \# pediatricians per enrollee & 0.10 & 0.20 & 0.00 & 1.50 \\
\hline \multicolumn{5}{|l|}{ Female enrollees aged 18-39 } \\
\hline$\%$ of all enrollees & 0.41 & 0.045 & 0.28 & 0.54 \\
\hline \# primary care doctors per enrollee & 0.09 & 0.20 & 0.004 & 1.60 \\
\hline \# OB-GYNs per enrollee & 0.02 & 0.05 & 0.0005 & 0.40 \\
\hline \multicolumn{5}{|l|}{ Female enrollees aged 50-69 } \\
\hline$\%$ of all enrollees & 0.09 & 0.02 & 0.04 & 0.16 \\
\hline \# primary care doctors per enrollee & 0.44 & 1.30 & 0.01 & 13.10 \\
\hline
\end{tabular}

Notes: The sample statistics for the financial performance variables and the control variables for the entire $\mathrm{HMO}$ are based on the sample used for well-child visits in the first 15 months. The variables for enrollees in the first year of life are used in the well-child visits in the first 15 months and the childhood immunization regressions. The variables for enrollees aged 1-4 years are used in the the regressions for well-child visits for 3-6 years. The variables for females aged 18-39 are used in the regressions prenatal and postpartum regressions. 
Table 2: Estimated Coefficients on Financial Performance Variable (OLS Regressions)

\begin{tabular}{|c|c|c|c|}
\hline HEDIS measure & $\begin{array}{c}\text { Profit } \\
\text { (PMPM) }\end{array}$ & $\begin{array}{l}\text { Med. exp. } \\
\text { ratio }\end{array}$ & $\begin{array}{l}\text { Admin. exp. } \\
\text { ratio }\end{array}$ \\
\hline Prenatal care & $\begin{array}{l}0.136^{* * *} \\
(0.046)\end{array}$ & $\begin{array}{l}-0.169 \\
(0.164)\end{array}$ & $\begin{array}{l}-0.311^{* *} \\
(0.128)\end{array}$ \\
\hline $\begin{array}{l}\text { Well child visits - } \\
\text { 1st } 15 \text { months }\end{array}$ & $\begin{array}{l}0.240 * * \\
(0.093)\end{array}$ & $\begin{array}{r}-0.258 \\
(0.192)\end{array}$ & $\begin{array}{r}-0.390 \\
(0.272)\end{array}$ \\
\hline $\begin{array}{l}\text { Well child visits - } \\
\text { 3-6 years }\end{array}$ & $\begin{array}{l}0.175^{* * *} \\
(0.040)\end{array}$ & $\begin{array}{l}-0.292 * * \\
(0.138)\end{array}$ & $\begin{array}{r}-0.090 \\
(0.096)\end{array}$ \\
\hline $\begin{array}{l}\text { Child immunizations - } \\
\text { DTAP }\end{array}$ & $\begin{array}{r}0.128 * \\
(0.063)\end{array}$ & $\begin{array}{l}-0.206 * \\
(0.112)\end{array}$ & $\begin{array}{r}-0.228 \\
(0.177)\end{array}$ \\
\hline $\begin{array}{l}\text { Child immunizations - } \\
\text { MMR }\end{array}$ & $\begin{array}{r}0.134 * \\
(0.077)\end{array}$ & $\begin{array}{r}-0.104 \\
(0.142)\end{array}$ & $\begin{array}{r}-0.254 \\
(0.232)\end{array}$ \\
\hline $\begin{array}{l}\text { Child immunizations - } \\
\mathrm{HiB}\end{array}$ & $\begin{array}{l}0.175^{* *} \\
(0.071)\end{array}$ & $\begin{array}{r}-0.218 \\
(0.127)\end{array}$ & $\begin{array}{r}-0.224 \\
(0.238)\end{array}$ \\
\hline $\begin{array}{l}\text { Child immunizations - } \\
\text { Hepatitis B }\end{array}$ & $\begin{array}{r}0.011 \\
(0.028)\end{array}$ & $\begin{array}{r}-0.033 \\
(0.099)\end{array}$ & $\begin{array}{r}0.084 \\
(0.185)\end{array}$ \\
\hline $\begin{array}{l}\text { Child immunizations - } \\
\text { VZV }\end{array}$ & $\begin{array}{l}0.163 * * \\
(0.073)\end{array}$ & $\begin{array}{r}-0.163 \\
(0.150)\end{array}$ & $\begin{array}{r}-0.327 \\
(0.250)\end{array}$ \\
\hline $\begin{array}{l}\text { Child immunizations - } \\
\text { Combination } 2\end{array}$ & $\begin{array}{r}0.044 \\
(0.047)\end{array}$ & $\begin{array}{r}-0.119 \\
(0.070)\end{array}$ & $\begin{array}{r}0.153 \\
(0.222)\end{array}$ \\
\hline Postpartum care & $\begin{array}{r}-0.060 \\
(0.044)\end{array}$ & $\begin{array}{r}0.098 \\
(0.075)\end{array}$ & $\begin{array}{r}-0.213 \\
(0.294)\end{array}$ \\
\hline $\begin{array}{l}\text { Breast cancer } \\
\text { screening }\end{array}$ & $\begin{array}{r}0.012 \\
(0.034)\end{array}$ & $\begin{array}{r}0.002 \\
(0.044)\end{array}$ & $\begin{array}{r}0.014 \\
(0.126)\end{array}$ \\
\hline \multicolumn{4}{|l|}{$\begin{array}{l}\text { Notes. This table shows or } \\
\text { performance measure. } \\
* * * \text { Significant at } 1 \% \text { level. } \\
* * \text { Significant at } 5 \% \text { level. } \\
* \text { Significant at } 10 \% \text { level. }\end{array}$} \\
\hline
\end{tabular}


Table 3: Estimated Coefficients on PMPM Profit (Instrumental Variable Regressions)

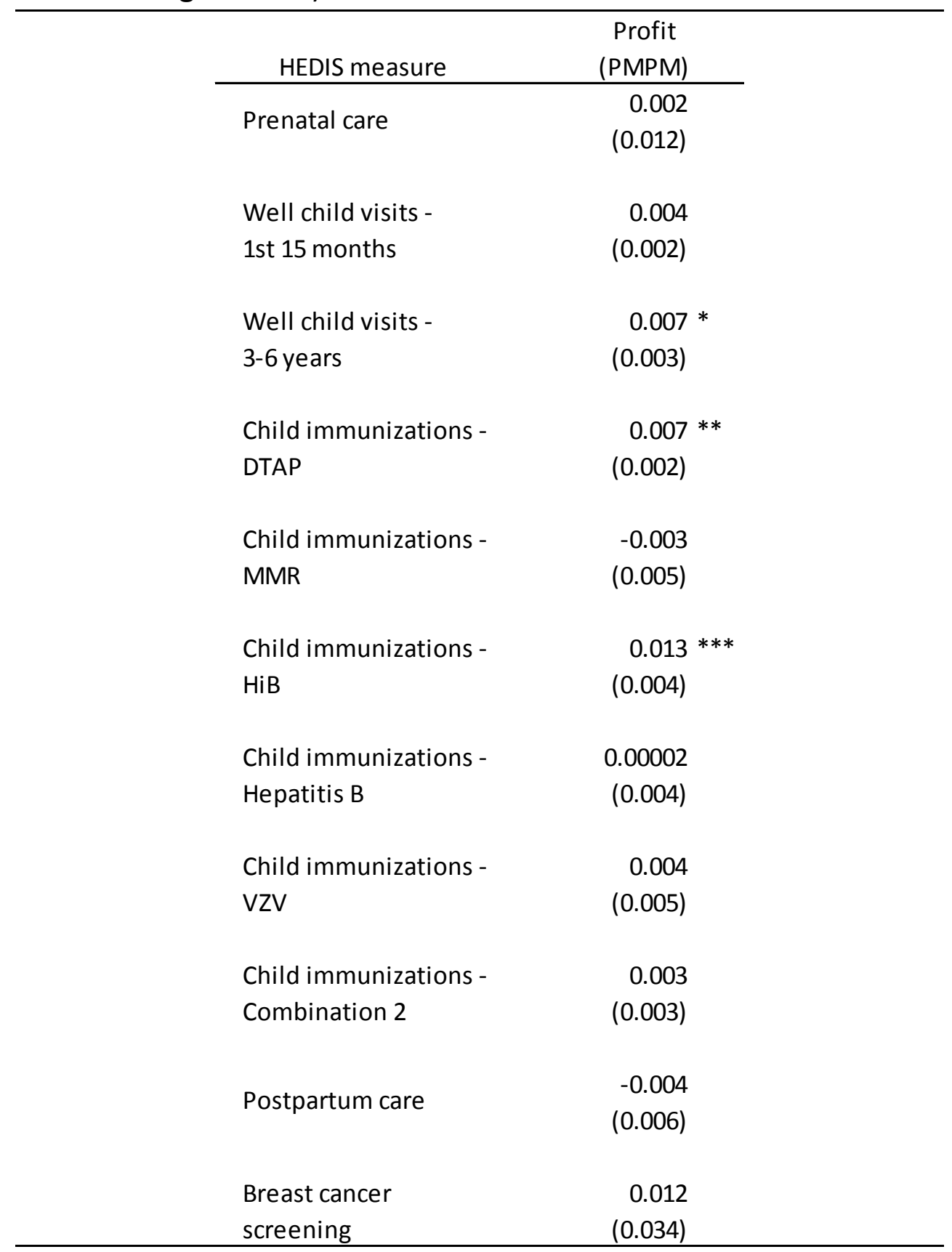

Notes. This table displays information on only the coefficient estimates on the PMPM profits. The top number in each cell is the coefficient estimate, while the bottom number is the standard error. The estimates are from the second stage regression in which the number of Medicare inpatient days was used as a instrument for PMPM profits in the first stage.

$* * *$ Significant at $1 \%$ level.

**Significant at $5 \%$ level.

*Significant at $10 \%$ level. 